\title{
FACEBOOK: LA IDENTIDAD CULTURAL DE LOS JÓVENES EN AISLAMIENTO SOCIAL POR COVID-
}

19

\section{(Facebook: The cultural identity in young people during the isolement social of COVID-19)}

\author{
Anny Bohórquez Vivas \\ abohorquez14@estudiantes.areandina.edu.co \\ https://orcid.org/0000-0002-5659-0252 \\ Fundación Universitaria del Areandina, \\ Colombia
}

\author{
Romelia Negrete Doria \\ rnegrete@areandina.edu.co \\ https://orcid.org/0000-0001-7388-1265 \\ Fundación Universitaria del Areandina, \\ Colombia
}

RESUMEN. El artículo identifica cómo se configura la identidad cultural de los jóvenes en Facebook en el aislamiento por COVID-19. Se describe a partir del uso de los medios sociales, que rápidamente se convierten en el recurso de comunicación juvenil. Por tanto, el acceso desde cualquier lugar, la flexibilidad e inmediatez permite a los jóvenes expresarse, participar, movilizar posturas en común e incluso ubicar amigos cercanos o distantes. Se toma como referencia las investigaciones de Galindo (2016), Boyd y Ellison (2007), Rueda, Giraldo, (2016), Muñoz, (2016), entre otros. La metodología es técnica cualitativa, a partir de publicaciones escritas, visuales en Facebook, en un grupo de jóvenes residentes en Bogotá. Entre los resultados se encuentran contenidos selectivos, expresiones en el léxico, ideologías y estados de ánimo de cómo asumieron el aislamiento y cuál ha sido la influencia de Facebook en algunos jóvenes que se muestran carismáticos con un perfil que ellos mismos han construido y creen único y que termina configurando su identidad cultural.

Palabras clave: aislamiento social, identidad cultural, jóvenes, Facebook, COVID-19.

ABSTRACT. The article identifies how the cultural identity of young people is configured on Facebook in isolation by COVID-19. It is described from the use of social media, which quickly become the youth communication resource. Therefore, access from anywhere, flexibility and immediacy allow young people to express themselves, participate, mobilize common positions and even locate close or distant friends. The research of Galindo (2016), Boyd and Ellison (2007), Rueda, Giraldo, (2016), Muñoz, (2016), among others, is taken as a reference. The methodology is a qualitative technique, based on written and visual publications on Facebook, in a group of young people living in Bogotá. Among the results are selective content, expressions in the lexicon, ideologies and moods of how they assumed isolation and what has been the influence of Facebook on some young people who are charismatic with a profile that they themselves have built and believe unique and which ends up configuring their cultural identity.

Keywords: social isolation, cultural identity, youth, Facebook, COVID-19. 


\section{Introducción.}

La juventud a menudo es considerada una etapa crucial de la vida, acusada ocasionalmente de rebelde e incomprensible por los adultos, ya que continuamente los jóvenes se enfrentan al niño dependiente de sus padres y el joven que anhela su espacio e independencia la busca, transforma y construye su Yo. Impregnada de nuevos aspectos distintivos, grupales, afectivos e identitarios contradictorios que intentan experimentar por sí solos, los jóvenes fortalecen y aprenden nuevas habilidades, establecen grupos con afinidades que responden a intereses individuales y colectivos irónicamente, intentando ser únicos, pero a la vez pertenecientes a una comunidad particular.

Es así que para Feixa (2006) quien realiza un recorrido histórico por la concepción de juventud del siglo pasado tenemos ese encuentro con los Boy scout, con los militantes del Rock and Roll, los hippies, los revolucionarios hasta llegar a la generación del siglo pasado que está más cerca a las nuevas generaciones, la generación de la red, las que tuvieron la oportunidad de presenciar el nacimiento de la internet y su auge mundial.

Para el autor mencionado "así como los baby-boomers de posguerra protagonizaron la revolución cultural de los años sesenta, basada en la emergencia de los mass-media y de la cultura rock, los niños y niñas de hoy son la primera generación que llegará a la mayoría de edad en la era digital" (p. 8). Y en este sentido para comprender el comportamiento de la sociedad actual es la generación red, esta es la testigo del nacimiento del fenómeno del internet que viene en su evolución desde el nacimiento de la física cuántica y las miles de investigaciones alrededor, para nadie es un secreto que las generaciones de los principios del siglo XXI están marcadas e inundadas de la virtualidad, por lo tanto es importante analizar el origen de la red (internet o virtualidad) para comprender la llamada nueva realidad Y en este ir y venir la información que circula puede ser atractiva y confusa. En palabras de Muñoz (2016): 
"Existe un sentimiento creciente de que nuestra experiencia de «ser sujetos», y por tanto nuestro concepto de «sujeto», está atravesando cambios significativos en el contexto de las sociedades contemporáneas orientadas hacia el consumo y marcadas por la cultura mediática y los avances tecnológicos. Internet, la música, las pantallas, son polos alrededor de los cuales se articulan identidades, lógicas y comportamientos. En mayor o menor medida asumen funciones de integración a órdenes sociales, proponen mundos valorativos y estilos, modelos de pensamiento y diversas formas de vida" (p. 73).

Es decir, la juventud recibe un choque emocional importante al intentar desprenderse de su niñez sin querer dejarla, a su vez acceder a una madurez que implica responsabilidades y un estado de relajación que el consumismo, la tecnología y la publicidad de su alrededor bombardea la construcción del sujeto que desea ser. Sin embargo, el desafío por ser reconocidos y aceptados los lleva a menudo a expresarse, presentar inconformidades o aceptaciones usando diferentes canales para validar sus opiniones a través de la red social Facebook (para este caso) mediante palabras, imagen (fotografías propias, tarjetas o memes) audio y video como alternativas de comunicación.

Este panorama resulta inquietante cuando la presencialidad es limitada y el uso de Facebook como facilitador es tal vez uno de los recursos preferidos para interactuar e identificar como asumen los jóvenes sus relaciones sociales, lo cual conduce a preguntamos ¿Cómo se configura la identidad cultural de los jóvenes a través de los medios sociales, Facebook en el aislamiento social por COVID-19? Los veinte jóvenes participantes en esta investigación se ubican al Sur Oriente de la localidad de San Cristóbal en la ciudad de Bogotá y pertenecen a diferentes instituciones de educación oficial en básica secundaria, media y universitaria, quienes sostienen comunicaciones en Facebook con amigos conocidos y por conocer. 
El acceso desde cualquier lugar, la flexibilidad e inmediatez permite a los jóvenes expresarse, participar, movilizar posturas en común e incluso ubicar amigos cercanos o distantes. Para Galindo (2016) "las redes digitales no son solamente un medio de expresión sino un nuevo escenario de disputa, de controversia, de visibilización y de comunicación, en suma, de puesta en juego de la correlación de fuerzas". (p. 14). Durante el aislamiento social por COVID 19 se intensifica el uso de esta comunidad virtual.

Prestando especial cuidado a cómo los jóvenes se ajustan a la digitalidad es posible identificar las características de las publicaciones que nos permitan describir las configuraciones identitarias a través de los medios sociales Facebook, contrastar los cambios en la configuración de la identidad cultural en la juventud antes (2019) y durante el aislamiento social COVID 19 (marzo a agosto de 2020) para finalmente, analizar el impacto de los medios sociales, Facebook en la configuración de la identidad cultural de la juventud durante el aislamiento social por COVID-19.

Si bien el aislamiento social por COVID -19 ha limitado las formas de relacionarse en la presencialidad, no ha sido un obstáculo para mantenerse informados, compartir con la comunidad virtual a la que pertenecen, "la espectacularización del yo consiste precisamente en eso: transformar nuestras personalidades y vidas (ya no tan) privadas en realidades ficcionalizadas con recursos mediáticos". (Muñoz, 2016: 78). El estudio evidencia, los cambios en las formas de comunicación, se comparte todo, se informa a la audiencia rutinas y anhelos con el fin de despertar admiración u oposición. Se percibe en particular como ellas actualizan con frecuencia y replican en Facebook a diferencia de los jóvenes que pueden aislarse de la red social Facebook por mayor tiempo (máximo tres meses).

Las publicaciones revelan quién es, aunque el sin fin de posibilidades incluso se convierta en perfiles peligrosos. Si bien los jóvenes lo diseñan a su parecer, se desconoce la veracidad de la información, para cautivar la atención de una audiencia particular las 
publicaciones se inclinan a ciertos tipos de personas generando riesgos para el portador de la cuenta y quienes le siguen. De acuerdo con Rodríguez y Magdalena (2015) citado por Domínguez (2018) afirma que:

"La mayoría de las redes sociales cuentan con opciones de privacidad, las cuales poco son consideradas entre los jóvenes, pues sería una barrera para ampliar su círculo de amigos o conocidos. Los usuarios tienen que ser poco selectivos en cuanto al contenido que publican; exponiendo su privacidad, haciendo uso indebido del mismo y siendo vulnerables en el mundo interactivo" (pág. 39).

En este sentido los jóvenes son amplios en aceptar o rechazar a los que como ellos buscan nuevos contactos y formas de relacionarse, y la privacidad es un tema que a veces los puede inhibir o alertar pero no los detiene, prefieren cerrar, bloquear o cambiar de identidad pero no desconectarse, es como perder un poco de su ser en el ciberespacio y a esto no le apuestan.

En la medida que el joven se aísla se desconoce en primera instancia su percepción del mundo real para presentarse a uno virtual igual o peor de peligroso, expone al portador partiendo que es este mismo que da rienda suelta a múltiples posibilidades carentes en el primer momento de análisis porque finalmente interesa es entretener a quienes lo ven y por consiguiente adquirir mayor cantidad de seguidores. Las opciones de privacidad se ignoran todo por una apariencia falsificada y soñada de un querer ser.

\section{Juventudes y redes sociales: Facebook.}

Es importante señalar en este punto la noción de nativos digitales y su polisemia de definiciones ya que sus características son susceptibles de variar en relación a circunstancias, espacio y tiempo, pero en general se usa el término según Cassany y Ayala (2018) se refiere a las personas que han crecido con teléfonos celulares, computadores y videojuegos y a su vez con acceso a las tecnologías de la información y 
comunicaciones que tal como lo afirma Diaz y Cabrales (2017) han generado cambios en la estructura del cerebro lo cual conlleva al desarrollo de habilidades específicas, formas de aprender y comunicarse que los distingue de otros grupos que prefieren las formas análogas o tradicionales de aprendizaje. Según Castells (2013) asistimos a una "sociedad en la que las condiciones de generación de conocimiento y procesamiento de la información han sido sustancialmente alteradas por una revolución tecnológica centrada sobre el procesamiento de información, la generación del conocimiento y las tecnologías de la información" (p. 1).

Frente a lo mencionado, es un hecho que los cambios sociales permean los habitus de los jóvenes en su conjunto y esto los obliga a reinventar cada situación que ve venir, así como en los modos en que adquieren saberes propios, por tanto, la identidad de todos los seres humanos especialmente los jóvenes, adquiere una nueva faceta para ser comprendida en los ámbitos en que se desenvuelven como son las redes sociales. En otras palabras, el uso de la tecnología digital y la red en particular Facebook interviene en forma directa en su entorno socioeducativo y por demás otros, adaptándolo a las demandas del presente siglo, aportando en forma transversal a sus procesos formativos que trascienden el campo escolar o el universitario.

El hecho de haber permanecido en casa en el tiempo de pandemia no quiere decir que la juventud se detuvo en sus comunicaciones e interacciones con amigos o cercanos, por el contrario, encontró en el acceso a las redes sociales y el Facebook una herramienta para el aprendizaje y diálogos no formales al punto de ser considerado una necesidad básica de lograr nuevos conocimientos en espacios de interconexión digital sin importar el lugar mientras se tenga acceso a una Tablet, computador portátil o smartphone y conexión a Internet.

Como lo afirman Small \& Vorgan (2009) sobre la tecnología digital que está cambiando nuestra forma de vivir y comunicarnos con tal vertiginosidad que provee a los nativos digitales de competencias comunicativas que han transformado las formas de aprender pero también de relacionamiento. Este desarrollo tecnológico ha ido 
transformando las formas de aprender y de pensar de los jóvenes de hoy, sobre todo, si se tiene en cuenta que, en la actualidad, un adolescente se pasa alrededor de cinco horas por día en frente de una pantalla o más, de tal forma que partimos que los seres humanos somos sujetos de interacciones físicas y sociales por naturaleza y esta situación inesperada (COVID-19) llevó a la humanidad a modificar las rutinas diarias, que por fortuna en las herramientas digitales como la red social Facebook intensifica la comunicación. En palabras de Boyd y Ellison (2007) citado por Roldan (2015):

"Las Redes Sociales son comunidades virtuales en las que las personas (usuarios) tienen la posibilidad de crear su propio perfil con todo tipo de información personal e interactuar con los perfiles de sus amigos de la vida real, también conocer a nuevas personas con las que comparten algún interés o no" (p. 12).

En este sentido, los jóvenes son atraídos por los recursos en línea interconectándose, sin límites en parte por la globalización y la generación de nativos digitales que necesariamente depende de las herramientas tecnológicas para socializar activamente, "el lenguaje conceptual es sustituido por el lenguaje perceptivo, considerado más pobre no solo por la disminución en el número de palabras, sino en cuanto a la riqueza de significados" (Muñoz, 2016: 82). Las publicaciones para los jóvenes deben ser contundentes y de fácil lectura, a la vez lo suficientemente creible que convenza y estructure un ideal del sujeto que desean ser.

$\mathrm{Al}$ parecer, todo es válido, hay una mezcla entre la realidad y la ficción, intereses y seguidores que de acuerdo al flujo de amigos que siguen a $\mathrm{X}$ joven, establece una popularidad particular y notoriedad en línea, mayor con respecto a la presencialidad. Así pues, Facebook es una de las redes sociales más activa en este campo ya que permite a los usuarios crear su perfil personalizado, con información como la educación, el sexo, la edad, entre otros. Además, brinda la posibilidad de 
escribir mensajes en las páginas de otros, compartir fotos, videos, etiquetar a los "amigos". El máximo de contactos "amigos" que permite es de 5.000, esto incluye amigos, familiares, conocidos o no (Herrera Harfuch, et al, 2010 en cita de Roldan, 2015).

Cada joven usuario decide cómo se presenta, a quien acepta y expresa su opinión, qué temas le apasionan, reconfigurando una identidad colectiva." El espectador se transforma en el nuevo usuario que entra a la red a buscar por su cuenta lo que necesita. (Muñoz, 2016, pág. 82) Ahora no por ignorancia sino por la necesidad de ser vistos acceden y comparten información que debe ser exclusiva de su portador. Así los y las jóvenes de esta investigación dejan ver es sus publicaciones contenidas que evidentemente debería ser estrictamente reservados. Como bien lo expresa en la investigación de Almansa, Fonseca y Castillo (2013) para:

"Los adolescentes colombianos pertenecer a un grupo de Facebook no es únicamente una manera de sentirse parte de algo, es tener una imagen en común que cobija a los miembros, que los protege, que les permite actuar como un «yo» colectivo. Ser parte de un grupo es pertenecer a una comunidad real" (p. 131).

En este sentido, ser joven y participar de la red significa construir un perfil, una imagen con el otro y para el otro, de modo que se rearma un sello identitario en este escenario que convoca a conocidos y aquellos que por amistades sugeridas se agregan y cada uno agrega su particularidad. Un sello que aparentemente es propio empero se alimenta de las percepciones de los demás y finalmente de aquello que desean mostrar como auténtico.

\subsection{En busca del sello personal: la identidad cultural.}

Al hablar de la incidencia del uso de la tecnología en las formas y modos de interacción social, de plano conduce a pensar en las practicas 
comunicativas en los que los sujetos que sin presencia física se interconectan al instante y es donde el fenómeno cultural reviste importancia llegando a repercutir en la construcción de identidad y los modos de representación y reconocimiento social en los espacios digitales posicionados como es el caso de Facebook en las redes sociales.

Algunos estudios en el tema cultural señala Hall \& Du Gay (2011) en cita de Vargas (2016) consideran a las identidades como un constructo en el interior de narraciones discursivas que surgen en los contextos sociohistóricos e institucionales que moldean la formación humana tanto cultural como material. Y resulta la identidad en el proceso de construcción de la historia personal en los escenarios físicos o virtuales se transforman o redimensionan (p. 15).

En distintos momentos los sujetos vuelven a contar su historia según sea la vivencia y la circunstancia vivida y son esos espacios que perfilan el encuentro consigo mismas y sus cambios o transformaciones. Es en ese sentido que en Facebook aparecen las historias de los participantes a través de fotos, imágenes, videos, memes, contenidos con carga emocional de modo que este discurso atraviesa diversos significados que comprende comunicación verbal, oral, simbólica y grafica en el marco de la red que actúa como un dispositivo mediador de la identidad.

En el proceso de construcción de estas historias se vislumbra la identidad. Las identidades se descubren a través de las historias personales. En efecto, cuando las personas cuentan historias, sus identidades se transforman o redimensionan. En este sentido, las historias de vida de los sujetos actúan como artefactos de identidad y como historias vueltas a contar, por medio de las cuales la persona se encuentra a sí misma y se transforma. En Facebook, las personas construyen sus historias de vida a través de muchos artefactos: textos escritos, fotos, vídeos, memes, etc. El discurso de las identidades en línea abarcaría no solo la comunicación verbal, sino también la visual y la multimodal (Yus, 2014). En un estudio sobre prácticas letradas vernáculas de estudiantes en Facebook, se argumenta que tales prácticas 
tienen un significado para la construcción de la identidad letrada de los adolescentes (Aliagas, 2015).

Resulta relevante que el Facebook se ubica como el de mayor preferencia entre los jóvenes al convertirse en parte casi imprescindible de su cotidianidad ya que facilita crear perfiles, compartir fotos, imágenes, comentarios, chat, memes con humor e incluso conformar comunidades particulares identificadas por intereses donde expresan sus motivaciones, tendencias y chateos.

De igual manera, la apropiación y uso de las TIC ha propiciado en los sujetos la creación de contenidos que faciliten el relacionarse en el ciberespacio implica a su vez el establecer protocolos para su regulación, pero también para comunicarse de manera específica y si se quiere sui generis entre los jóvenes.

Es en ese sentido que la identidad cultural se reconfigura como un componente de la ciudadanía digital de interacción humana, de expresión y producción simbólica en correlación con el lenguaje digital donde surge nuevas formas de expresar y configurar la identidad y la ciudadanía. Los jóvenes encuentran en el ciberespacio el entorno para tener voz, hacer valer derechos, plantear exigencias, humor, aportar y manifestar ideologías en diversos campos, siendo otra expresión de reconfigurar sus preocupaciones identitarias.

Para Ortega (2015) la ciudadanía digital es una forma en que los ciudadanos participan, interactúan y reflexionan e invita a pensar en otras dimensiones donde las tecnologías permiten apropiarse de la realidad y convertirse en elemento de construcción de identidad al facilitar a las personas y este caso a los jóvenes el acceso a la comunicación interpersonal, generando el otro o receptor sentimientos de cercanía y momentos de compartir estados de ánimo, sentimientos al conocer en tiempo real la reacción frente al mensaje y lo que produce en su interlocutor

Así pues, la identidad cultural de los y las jóvenes es construida en un modelo colectivo en línea que curiosamente cada palabra, imagen, video o fotografía resulta ser tan cercana a su contexto incluso si no son los artífices de estas. La identidad comprende tres dimensiones: primero, 
una dimensión ligada a las intenciones de (re)presentación del individuo frente a los otros; segundo, una dimensión relacional asociada a las interacciones con el círculo social inmediato; y tercero, el conjunto de roles que asume y desempeña el individuo de acuerdo con el entorno en el que se encuentra. Crear una autoimagen y presentarse ante otros es por tanto una combinación de elementos: símbolos, interacciones y contexto (Rueda, Giraldo, 2016: 121).

Evidentemente, estos tres elementos acceden a Facebook en una armonía apacible que incluso aquellos personajes introvertidos en la presencialidad logran protagonismo tras pantallas. En la búsqueda de la aceptación, la apariencia ya sea visual o escrita asume el protagonismo que las conversaciones face to face limitan, por tanto, pasar horas frente a un ordenador explorando la mejor postura que refleje lo que son, implica un celoso cuidado. En palabras de González (2000) citado por Avendaño (2017) la "identidad cultural es su carácter inmaterial y anónimo, pues son producto de la colectividad” (p. 23). En primera instancia no es como se relacionan sino cómo los ven y quien los ven.

En este sentido, la identidad cultural se convierte en un asunto dinámico y continuo de acierto y error que depende de las perspectivas del otro, a fin de cuentas, es relevante los "me gusta" que a manera de censo válida, rechaza y dicta un precedente. Sin embargo, la identidad colectiva no se resume únicamente en imágenes o textos. En Facebook las narrativas de vivencias son sonoras e ilustrativas que a través de videos expresan sentimientos, agradecimientos e incluso frustraciones. Las historias de vida son multimedia. En palabras de Vargas (2016) partiendo de las posturas de pedagogía crítica (Freire y Macedo, 1989) y feministas "la identidad, nos invitan a vernos como personas que, en el flujo de la vida se forman histórica, social, cultural y materialmente" (p. 15). La virtualidad permite recorrer espacios inexplorados, a veces por las juventudes.

Facebook, por tanto, es un comunicador de experiencias. Cada participante añade a la mezcla su apreciación, estructura una gran comunidad diversa, ahora de carácter global e inmediato con alta demanda en sus contenidos que en la actualidad son formalizados en 
canales comunicacionales asertivos de divulgación académica y cultural a par del entretenimiento y ocio. Como expresa Reateguí (2020) refiriéndose a contenidos visuales sobre ciudadanos incumpliendo las medidas de aislamiento por COVID-19 "los usuarios comparten los videos en sus perfiles con el fin de concientizar a sus contactos, mientras otros buscan generar debate alturado y conocer posturas distintas a la suya" (p. 15). Un asunto que modela posiciones diversas intentando ser visualizadas, compartidas y destacadas.

\subsection{De la presencialidad a la web: Transformar el aislamiento (COVID-19).}

Adultos, jóvenes y niños acuden a la red, con un aparato tecnológico dotado de un explorador y algunos buscadores, es suficiente para pasar horas si se quiere, navegando por un mundo cibernético de imágenes, textos multimediales, lecturas e incluso videojuegos adaptados a diferentes públicos. La permanencia cada vez es mayor, en consecuencia, Facebook absorbe cantidades exorbitantes de tiempo hasta más de 5 horas al día que quizás su uso debería prolongarse en otras actividades presenciales como lecturas de libros, caminatas, ejercicio, reuniones con familiares y amigos.

Ahora, si desean mantener una conversación fluida con un joven solo se requiere estar conectados a Facebook, tener un arsenal de emojis, memes, videos y cámara para que el intercambio de pensamientos y palabras sean atendidos por la juventud acertadamente. En palabras de Mohseni, et al. (2008) citado por Benítez, Cortés y Hernández (2016) “el aislamiento social es una situación en la que una persona carece de vínculos sociales para conseguir el apoyo social necesario, se presenta cuando una persona, en este caso el adolescente, se aleja totalmente de su entorno" (p. 25). Y no es para menos, si el ambiente es pesado, agotador, estresante o aburrido, la virtualidad atrapa con sus contenidos en línea, compartidos, divertidos e incluso graciosos. Como lo menciona Mohseni, et al. (2008) citado por Benítez, Cortés y Hernández (2016): 
"En países de primer mundo como Estados Unidos y Japón se usa el término de "screenagers" o "bedroom culture", que hacen referencia a los adolescentes que pasan gran parte de su tiempo ante estas tecnologías, ya que, las habitaciones de los adolescentes son espacios privados donde no acceden adultos y, que están equipados con tecnologías, permitiéndoles encerrarse y tener contacto con el mundo exterior solo mediante esta" (p. 26).

Sin embargo, en medio de esta situación adultos pretendiendo que sus jóvenes participen activamente en la presencialidad y los jóvenes obedeciendo en la virtualidad, ningún ser humano consideró una sociedad mayormente digital a causa de enfermedades que impidieran las relaciones cara a cara. El COVID-19 transformó la manera de ver la web, los grupos de estudio, trabajo, amistades han sido drásticamente modificados, reducidos a pantallas de ordenadores y teléfonos inteligentes, por responsabilidad social, familiar y personal.

Una angustia permanente que siempre ha estado presente acerca del futuro que golpea en plena era de relaciones sociales a los jóvenes y que por su cuenta deben enfrentarse asumir y resolver, buscar ventaja, e incursionar en una vida cada vez más dependiente de la digitalidad. Sin embargo, las alternativas que proponen Ramírez et al. (2020) se encaminan a un cambio de perspectiva que implica:

"Incentivar y apoyar el pensamiento de corte positivo sobre el futuro y educar en técnicas para disminuir niveles de estrés y de hiperactivación como la respiración profunda o diafragmática, relajación muscular progresiva e imágenes guiadas... Medidas que pueden tener impacto para afrontar las dificultades propias del servicio, estarán encaminadas en reflexionar y aprender de las experiencias difíciles para crear una narración significativa en lugar de traumática dentro de lo cual está compartir la experiencia con un compañero, implementar de forma sistemática y organizada horarios de 
descanso, además de eventos en los que se aprecie y se reconozca continuamente de forma verbal los esfuerzos" (p. 13).

En relación con lo mencionado, el aislamiento ocasionado por la pandemia (COVID- 19) ha acelerado las nuevas formas de interacción digital entre los jóvenes, esta se ha convertido en un paliativo para afrontar la soledad derivada de la poca experiencia física con sus pares. En suma, la red es la protagonista que convoca a nuevos escenarios, experiencias, eventos donde confinamiento y distancia son invisibles al sostener un hilo socioemocional de comunicación. Con respecto al tema Canales (2020) sostiene que:

"Las personas requieren estar al tanto de las noticias que afloran constantemente sobre el tema de coronavirus, aportan y reciben información lo que genera una interacción entre ellos...es una herramienta informativa y de recepción de opiniones e inquietudes, las cuales manifiestan están siendo registradas para darles respuesta posteriormente" (p. 16).

Mantener la mirada en lo sucedido y por venir invita en cierta medida a adultos y jóvenes a acercarse a la situación, aunque estas sean tergiversadas. En principio se espera estar informado para ser parte del tema de conversación y en segunda medida para establecer patrones de pánico (en ocasiones) o activar las alarmas, incluso para ser incluidos en la crítica sin perder el hilo que el momento convoca a todos, claro está el joven desde su facilidad través de cortos mensajes o visualizaciones de videos que informe concretamente, ya que la estadía en la red es mayormente dedicada al ocio. 


\title{
3. Metodología.
}

\subsection{Técnica cualitativa.}

Esta investigación parte del enfoque cualitativo, presenta una aproximación de carácter subjetivo en los jóvenes que postulan alternativas como que "la realidad" se define a través de las interpretaciones de los participantes en la investigación respecto de sus propias realidades. De este modo convergen varias "realidades", por lo menos la de los participantes, la del investigador y la que se produce mediante la interacción de todos los autores. Además, son realidades que van modificándose conforme transcurre el estudio y son las fuentes de datos (Hernández Sampieri, Fernández y Baptista, 2010). La aproximación a diferentes formas de ver los implicados, como asumen su diario vivir, permite al investigador aproximarse sin alterar su postura, identificar algunas claves para comprender las nuevas realidades y debatirlas en busca de comprensiones en los cambios sociales de las juventudes.

\subsection{Tipo de investigación.}

El tipo de investigación es de carácter hermenéutico. Ángel (2011) afirma que:

\begin{abstract}
"La hermenéutica resuelve el problema que deja abierto la fenomenología mediante la concepción del círculo hermenéutico, es decir, mediante la confrontación constante, en un proceso de diálogo, en el cual los dialogantes están abiertos siempre al ser del otro, y que tiene como resultado un saber que es punto de vista en el cual ya nadie puede reclamar su cuota, su porción, porque el resultado es nuevo y es histórico" (p. 20).
\end{abstract}

Así pues, la hermenéutica intenta comprender, no concluir el debate como instrumento de reflexiones y aprendizajes que amplíen la perspectiva de las juventudes, sus alcances, necesidades, nuevos escenarios y modos de diálogo que mediante Facebook, potencian 
relaciones sociales identitarias fuertes entre amistades construidas en la presencialidad y nuevas desde la virtualidad como elemento de intercambio durante el confinamiento por el COVID-19.

\subsection{Contexto y muestra.}

La población para esta investigación está conformada por 20 jóvenes entre 14 a 20 años de edad residentes en la Localidad Cuarta de San Cristóbal al Sur Oriente de la ciudad de Bogotá, de estrato socioeconómico 1 a 3, que en la herramienta de Facebook se aceptan como“ amigö. El 74\% de los participantes estudian en colegios oficiales en la básica secundaria o media. Adicionalmente tres de los participantes son egresados de colegio oficiales y se desempeñan en un oficio, ya sea porque se capacitaron o encontraron una opción de empleo. Una de las participantes es madre joven y finalmente dos jóvenes más son egresados de colegios no oficiales que en la actualidad asisten a la universidad. Cada uno de los jóvenes cuenta con un aparato tecnológico ya sea propio (13 participantes con celular), o de un familiar el cual es compartido (ocho), computador (trece) para interactuar en la plataforma de Facebook (Cuadro 1).

\section{Cuadro 1. Herramientas digitales de interacción.}

\begin{tabular}{c|c|c}
\hline $\begin{array}{c}\text { Dispositivo } \\
\text { tecnológico }\end{array}$ & Condición & Cantidad \\
\hline Celular & Personal & 12 \\
\cline { 2 - 3 } & Compartido & 8 \\
\hline Computador & Compartido & 13 \\
\hline
\end{tabular}

Fuente: elaboración propia (2021).

La familia de los jóvenes de este estudio está conformada por dos grupos: nucleares (ocho) y monoparentales (12). Entre los participantes ocho son hermanos que conviven juntos (Cuadro 2). 


\section{Cuadro 2. Grupos familiares.}

\begin{tabular}{c|c|c}
\hline Conformación familiar & Cantidad T. & Hermanos \\
\hline Nuclear & 8 & 4 \\
\hline Monoparental & 12 & 4 \\
\hline
\end{tabular}

Fuente: elaboración propia (2021).

Este grupo de trabajo (veinte participantes) responde bajo autorización firmada por acudientes y/o cuidadores a la convocatoria interna por Messenger o WhatsApp para la presente investigación. Es decir, solamente aquellos que manifestaron su deseo por querer participar hacen llegar el consentimiento vía electrónica y mantiene continua comunicación virtual con las investigadoras. A la convocatoria de treinta y cinco participantes, solamente veinte de ellos cumplen con los requisitos para acceder a sus perfiles y por ende a participar de este proceso investigativo. Adicionalmente, es necesario rescatar que entre ellos compartían y comparten espacios de socialización presencial, se conocen entre sí y la plataforma digital Facebook les ha permitido durante el aislamiento mantener contacto digital.

\subsection{Materiales.}

Desde el método hermenéutico con enfoque interpretativo y comprensivo, el primer momento consiste en establecer contacto en la plataforma Facebook por Messenger o WhatsApp. Se realiza observaciones de estado, publicaciones del año 2019 (octubre a diciembre) y de 2020 (entre marzo a agosto) en forma periódica, se revisa durante tres o cuatro días a la semana para contrastar la frecuencia de la publicación, tipo de mensaje, réplicas antes y después de la pandemia. Así mismo, se analiza las interacciones, publicaciones y tiempos de permanencia en la red (testigo de color verde que indica actividad en la plataforma) para reconocer las reacciones del portador de la cuenta y sus seguidores.

Después de contrastar la información del año 2019 y el periodo de aislamiento por COVID 19 entre marzo y agosto. Un segundo momento consiste en aplicar una encuesta de cuatro preguntas de 
selección múltiple y cuatro abiertas con consentimiento informado de los padres o participantes para recoger información sobre las percepciones de los jóvenes con respecto al uso de Facebook. El tercer momento es la interpretación y el análisis comprensivo de los resultados.

\section{Resultados y discusión.}

Considerando la perspectiva de los sujetos participantes del estudio los jóvenes, presentamos alguno de los resultados más significativos relacionados con los perfiles, los comentarios, las imágenes, el contenido escritural, el meme como expresión emocional, estado de ánimo y humor.

Es inevitable mencionar entre los resultados el tipo de espacio que representa Facebook como sitio de entretenimiento y esparcimiento que mitiga sensaciones de angustia, frustración, felicidad y por supuesto articuladas contribuyen a dar configuración a la identidad como ciudadanía digital entre los jóvenes que no cesan en su búsqueda y delimitación personalizada aun en la interacción ciberespacial. A continuación se describe los resultados a partir de las categorías como perfiles, identidad e interacciones emocionales, lugar de comunicación, relacionamiento y esparcimiento.

$\mathrm{Al}$ interpretar los perfiles de los participantes se encuentra que las fotografías en los jóvenes (masculino) se denotan personajes de videojuegos, aficiones, habilidades o lugares visitados (ver imagen 2). En las jóvenes refieren la belleza como principal indicador aquella descrita en video, fotografías y comentarios entre jovencitas. Le siguen personajes que admiran (ver imagen 1).

En consecuencia, el flujo de publicaciones es mayor en mujeres. Mantener a la audiencia informada de los cambios físicos prevalece, ya que los jóvenes tienen la necesidad de experimentar con su propia autoimagen más allá de las reglas establecidas, escenificando y transformando su imagen para ser publicada principalmente en los álbumes digitales a través de la plataforma (Rueda y Giraldo, 2016, p: 133). Si esto es así, la belleza adquiere un protagonismo fundamental en la mujer joven, símbolo de seguidores y vistas. 


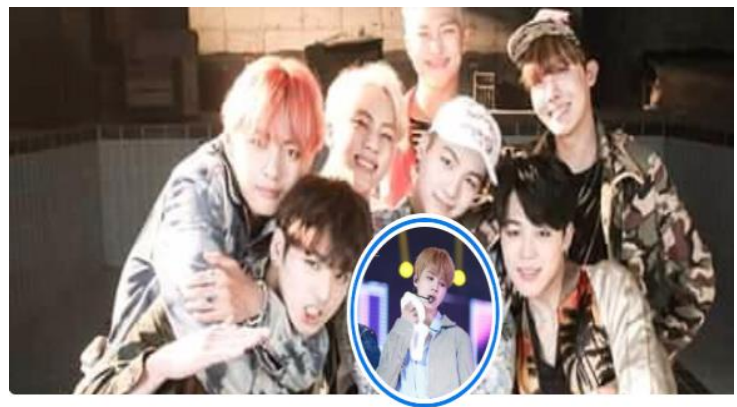

Imagen 1. Aficiones. Imagen de perfil.

Fuente: grupo focal (2021).

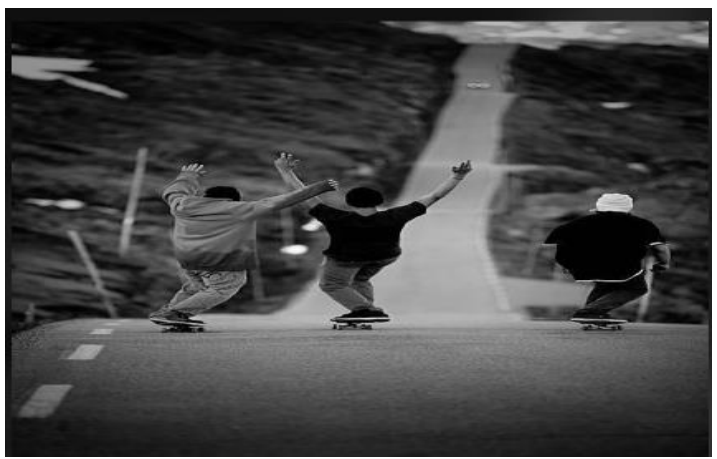

Imagen 2. Habilidades e intereses del aislamiento.

Fuente: grupo focal (2021).

No obstante, la cantidad de publicaciones periódica aumenta notoriamente con respecto al año anterior, convirtiéndose en una actividad diaria, se revela intereses del momento que se perfeccionan de modo que los jóvenes se redescubren en el aislamiento, por consiguiente, lo transmiten a manera de comentario o revelación con el fin de ser exaltados por su séquito de seguidores. Algunos ejemplos son skateboard, lectura y danza.

Otro aspecto relevante tiene que ver con el nombre, datos básicos, incluso comentarios, los cuales mantiene un lenguaje de la red 
acompañado de diéresis, letras invertidas, tildes a manera de separador, emoticones, nuevas palabras que suprimen letras o combinan con otras culturas y errores ortográficos. Muñoz (2016) en su publicación “jóvenes digitales" argumenta que:

"La escritura inmaterial, virtual, mata el aura técnica, esa cualidad del texto original, irrepetible. En los nuevos espacios de Internet se cultiva un tipo de escritura con fuertes marcas de oralidad: es habitual el recurso a la transcripción de la fonética y un tono coloquial que evoca las conversaciones cotidianas, con cierto descuido, de carrera y con brevedad, abusando de las abreviaturas, siglas y emoticonos, sin ortografía ni signos de puntuación, con vocabulario limitado; paradójicamente es la «muerte de la conversación» (Debord) de la escritura y de la lectura (Chartier)" (p. 85).

Evidentemente la escritura atraviesa por un periodo al igual que el joven, de transformación que resulta atrayente e incluso se mantiene como un sistema cifrado de comunicación que los identifica como parte de un grupo, con autonomía propia y originalidad. Existe empero, un afán por encontrar identidad en el grupo que los motiva a replicar y recrear lo que otro antes publicó y prosiguiendo con el análisis no es una originalidad propia la que surge sino colectiva, producto de su auto concepto sobre sí mismos.

Más no se trata tan solo de la «muerte de la conversación» (Debord) de la escritura y de la lectura (Chartier) con cita de Muñoz, (2016:85), de la cantidad de palabras con cualidades y tecnicismos ahora por el contrario la conversación adquiere un aura de brevedad que por un lado la hace más llamativa y exige nuevas interpretaciones por su significado y significante. A su vez, como lo explica Vargas (2016) las historias de vida de los sujetos actúan como artefactos de identidad y como historias vueltas a contar, por medio de las cuales la persona se encuentra a sí misma y se transforma. En Facebook, las personas 
construyen sus historias de vida a través de muchos artefactos: textos escritos, fotos, vídeos, memes, etc. (p. 15).

Es por esto que durante la primera etapa del aislamiento (abril a mayo) las publicaciones son cargadas de la extrañeza y ausencia de amigos principalmente, lugares y familia, (ver imagen 3) lo cual resulta pasajero, para más tarde convertirse en críticas o burlas como el cambio de clases presenciales a virtuales y sus implicaciones (ver imagen 5 y 6 ) como el acompañamiento permanente en casa, con familiares.

Para Van Dijck (2008) quien aborda estudios en juventud, identidad y el uso de los medios digitales se denota la utilidad del internet en la vida cotidiana de los jóvenes al ofrecer recursos digitales simbólicos para construir como jóvenes sus propias identidades, pues son ellos los que viven con gran intensidad los medios digitales como una forma de expresar y vivir nuevas formas de exploración identitarias que modelan el mundo actual. Afirma la autora:

\section{"Not coincidentally, the camaraphone merges oral and visual modalities the latter seemingly adapting to the former. Pictures become more likes spoken languages as photographs are turnining into into the new currency for social interaction. Pixeled images, like spoken words, circulate between individual and groups to establish and reconfirm bonds. Sometimes pictures are acompanied by captions that form "missing voice" explaining that picture" (p. 6 y 7).}

De este modo no hay nada por fuera del ciberespacio que no sea validado por los jóvenes en sus interacciones digitales, encontrando en la respuesta su reconocimiento a la idea, la imagen o el meme siendo parte de las prácticas sociales en la que están sumergidos los jóvenes y cuyas prácticas como lo observa Giddens (1991) “son alteradas y maleables en vez de estáticas o fijas” (p. 28), siempre nos están acompañando junto a las otras personas con quienes se interactúa. En el caso de Facebook la identidad incluye más que un acto volitivo ya que la información es provista por los otros, los que leen, responde y reaccionan (amigos, familia, medios, etc.) otorgando una complejidad que trasciende a la 
interacción cotidiana del día a día. Existe una transversalidad entre la estrategia del usuario de la red y la plataforma Facebook en la que se cruzan muchos usuarios de la red. En este sentido lo sostiene Rueda y Giraldo (2016) "es necesario tener en cuenta en el mismo nivel, las dimensiones técnicas y sociales" (p. 124).

Otros ejemplos, es la reacción a noticias mediante el meme (ver imagen 4) y a nombres en función de cualidades propias con humor sarcástico, expresiones como "arroz con leche" y su descripción de perfil “11:11: bajaré a raspar la pega del arroz. 11:12: con tinto", es el seudónimo para ser reconocida y hacer visual una nueva identidad. No se establece un tema particular, son relativos de índole informativo, gracioso e intelectual.

\subsection{El meme en función de identificar auto cualidades entre los jóvenes.}

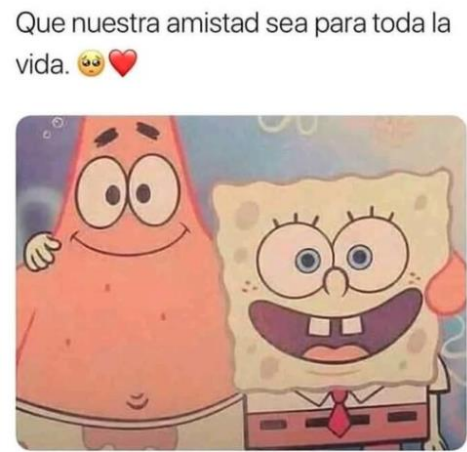

\section{Imagen 3. Sentimientos de nostalgia.}

Fuente: grupo focal (2021), compartida en Facebook en abril 2020. 


\section{Imagen 4: Social.}

Fuente: grupo focal (2021), compartida en Facebook en abril 2020.

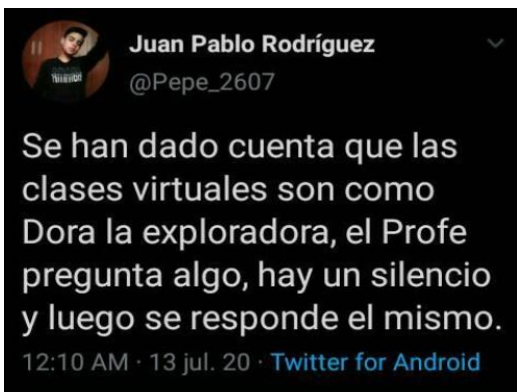

\section{Imagen 5. Clases virtuales.}

Fuente: grupo focal (2021), compartida en Facebook en agosto 2020.

Hijole profe, yo creo que no le voy a poder enviar la tarea, no prende mi laptop

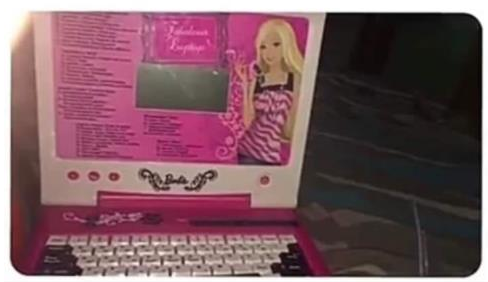

\section{Imagen 6. Clases virtuales.}

Fuente: grupo focal (2021), compartida en Facebook en agosto 2020. 
Avanzando en esta reflexión, los jóvenes no se detienen en la construcción de una identidad virtual que poco a poco se va personalizando y definiendo rasgos de un yo, otro y otros para reafirmar su existencia a través de la red Facebook. Si esto es así, jóvenes y redes construyen juntos nuevas formas de ser y estar temporal y espacialmente a pesar de las vicisitudes. Es por esto que el medio comunicacional de preferencia por los jóvenes es el meme, como instrumento para animar, relacionarse, conversar, criticar y reaccionar tal como lo confirma la encuesta realizada a los 20 participantes (Gráfico 1), además de otras expresiones: Fotografías, videos, emojis, etc.

\subsection{Expresiones utilizadas por los jóvenes como instrumento de animación y relaciones.}

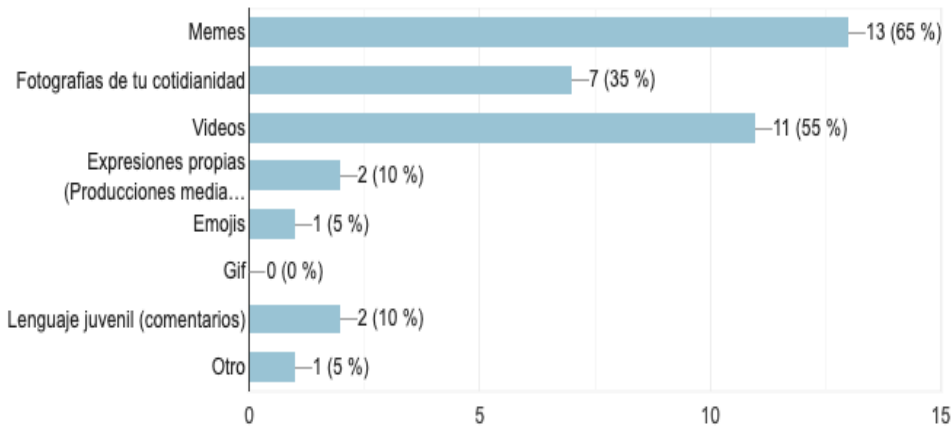

Gráfico 1. Preferencias de los jóvenes por los diferentes medios de expresión.

Fuente: elaboración propia (2021).

De los encuestados, un 65\% prefiere compartir meme como respuesta a mejorar el ambiente emocional de quienes lo visualizan e incluso el propio, ya que transmite alegría encapsulada en la burla por sí mismo o por el otro. Cuando los jóvenes publican en Facebook expresan felicidad ( $95 \%$ de los encuestados) como se observa en el Gráfica 2. 


\subsection{Uso del meme como respuesta emocional de los jóvenes.}

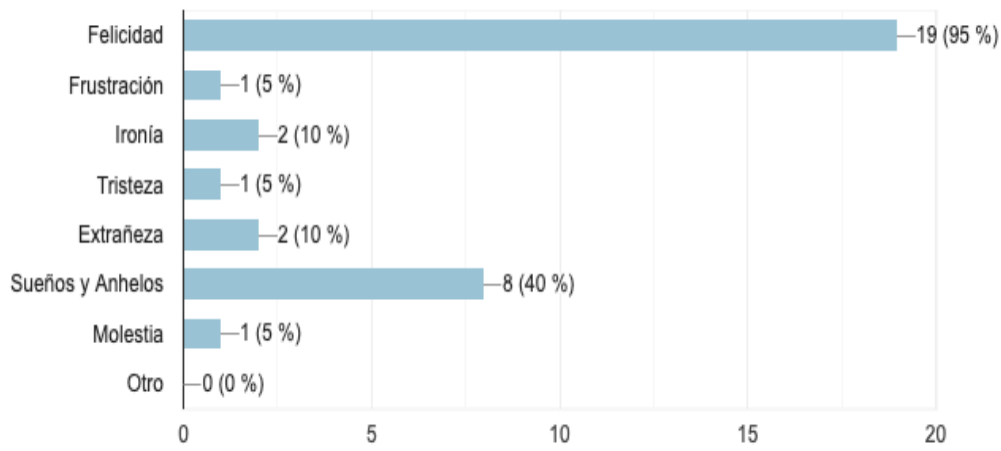

Gráfico 2. Sentimientos y emociones que acompañan las publicaciones.

Fuente: elaboración propia (2021).

Un segundo estado de ánimo es reflejado en sueños y anhelos (8\%). El meme a su vez, crea lazos mediante el sarcasmo, la aprobación del otro y su simpatía con el publicador. En palabras de Reyes y Sosa (2017), "En el caso de los memes, el humor es uno de los elementos notables para ganar favoritismo, especialmente en los adolescentes" (p. 10). A través de un meme se establecen conversaciones, apuntes o negaciones que activan la participación y refleja en parte la personalidad de quienes participan (ver imagen 7). 
4.4. El meme como expresión de humor y personalidad de los jóvenes.

\section{Cuando el Coronavirus estaba atacando sólo a las potencias mundiales y de repente llega a Latinoamérica.}

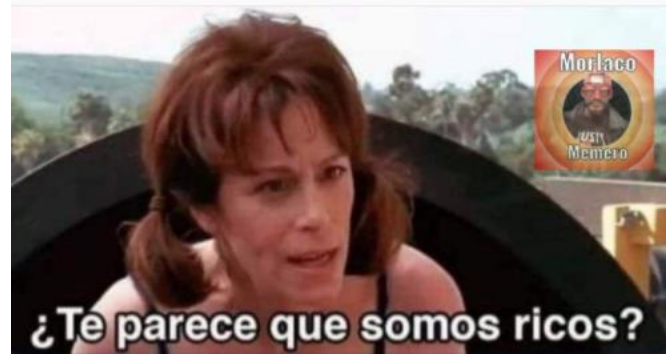

Imagen 7. Aviso de COVID-19 en Latinoamérica.

Fuente: grupo focal (2021), compartida en Facebook en febrero 2020.

Otro elemento detectado en el meme es su fin político y social. Para Canales (2020):

"Facebook crece diariamente y a un ritmo acelerado, por tanto, ya no es únicamente para comunicarse con conocidos es también para abarcar de manera global problemas sociales de los cuales se debata a nivel global, transmitiéndose opiniones, sugerencias y soluciones de forma viral entre la población de todo el mundo; especialmente entre los más jóvenes que siempre están conectados y son muy activos en las redes sociales" (p. 16).

Anteriormente el afiche y la caricatura expresaba las influencias políticas, económicas y sociales el malestar a favor de excentricidades e injusticias, hoy el meme adquiere un gran impacto en la sociedad que influye en las opiniones, aproxima la juventud con su realidad, la observa, interpreta y genera posiciones que en ocasiones puede ser 
nuevamente replicadas con el mismo método ya sean creados o simplemente por medio del comentario, emoji o avatar.

La ausencia de relaciones afectivas entre los jóvenes durante el confinamiento, destacó la extrañeza de espacios de socialización: colegio y universidad arrojó el mayor indicador (50\%) como un espacio distinto de encuentro, donde se comparte, escucha y aprende. Para el $40 \%$ de los encuestados la diversión y entretenimiento juegan un papel importante ya que, estar frente al otro les garantiza tranquilidad y libertad. En menor proporción resulta las reuniones de grupo (10\%). (ver Gráfico 3).

\subsection{Tipos de espacio y entretenimiento que suple la red social entre los jóvenes.}

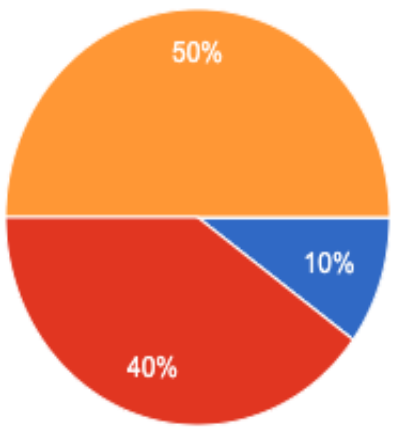

Reuniones de grupo

Diversión y entretenimiento

Colegio o Universidad

Otro

\section{Gráfico 3. ¿Qué extrañas antes y durante del confinamiento?}

Fuente: elaboración propia (2021).

Conforme a lo observado, la red social Facebook ha sido el puente para mantener desde la virtualidad comunicación con quienes están distantes causando una notoria influencia en tendencias y gustos. Es decir, que sus intereses, depende en gran medida de lo visto, publicado, comentado y escuchado mediante la red. En el estudio realizado por Almansa, Fonseca y Castillo (2013) identificaron que en jóvenes de España y Colombia entre 12 a 15 años, permanecer en la red es una necesidad y es relevante presentarse originales desde la mirada de 
"originalidad" que entre ellos mismos construyen y expresan mediante imagen, texto, modos de escritura, fotografías retocadas, identidades falsas (en oportunidades) y publicaciones. (p. 133). En otras palabras, se comprende que al otro lado de la pantalla también hay un ser sensible, auténtico y reacciona a situaciones similares o incompatibles pero que está presente. Se confirma lo anterior con el Gráfico 4.

\subsection{Facebook y su incidencia en configurar la identidad en los jóvenes.}
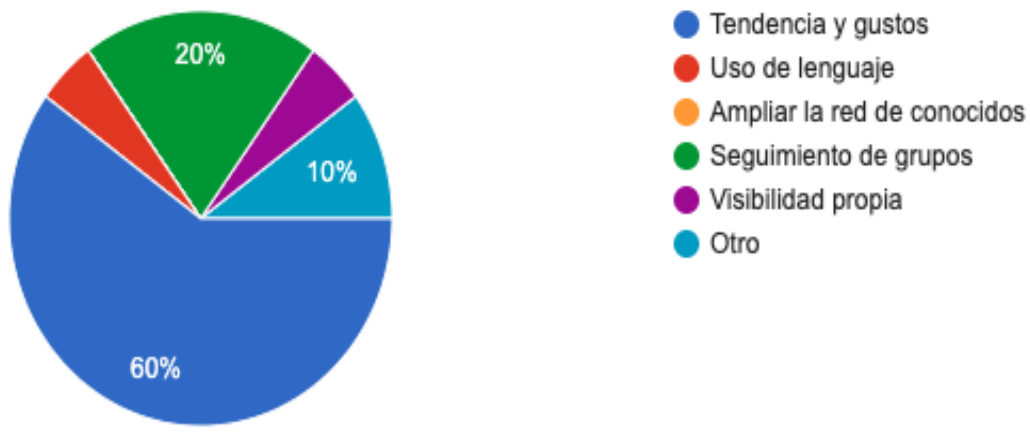

Gráfico 4. Influencia de Facebook en su identidad.

Fuente: elaboración propia (2021).

La influencia de Facebook en la construcción de la identidad cultural de los jóvenes es decisiva, existe la individualidad que se comparte y refuerza en la virtualidad colectivamente. En palabras de Molano (2007) como cita Avendaño (2017) "La identidad no es un concepto fijo, sino que se recrea individual y colectivamente y se alimenta de forma continua de la influencia exterior" (p. 34). Cada participante aporta esperando ser retribuido con "me gusta" (like), comentando o manteniendo la línea de intereses. 


\section{Conclusiones.}

A manera de conclusión, Facebook es llamativo, permite con la palabra clave (nombre) o un amigo relacionado acceder a la información de quién buscas rápidamente. Un chismógrafo que en otro momento se escribía en cuadernos y se rotaba, ahora la web lo perfecciona abriendo la posibilidad de expresar mediante diferentes recursos, estados de ánimo y anhelos según cómo quiere ser reconocido o visualizados.

Los jóvenes de esta investigación con frecuencia acceden a sus perfiles, agregando intereses individuales que la comunidad Facebook aprueba o desaprueba. En este sentido se construyen nuevas formas de ser vistos, las publicaciones lo confirman, seguidores, comentarios y los grupos a los que pertenecen, una construcción identitaria dependiente de las visualizaciones, los 'me gusta', la originalidad y los sarcasmos que se colectiviza con un alcance a escala global.

La identidad cultural en los jóvenes se configura con la dependencia de la virtualidad, por tanto, se enfrentan al sincretismo digital adsorbente y altamente socializado, las múltiples facetas impiden su alcance y percepciones porque en la complejidad de sus usuarios cualquier aporte es posible. Como alternativa de reconocimiento se intensifican los tiempos de pantalla los jóvenes expresan e informan que ha sucedido con sus vidas y las afectaciones del aislamiento. Así lo expresa Ximena: "A pesar de la distancia, hay personas que te hacen la cuarentena más bonita".

No obstante, los memes ratifican el impacto de una sociedad mayormente presencial que a la fuerza obliga un confinamiento inesperado, angustiante y sin equipamiento, como lo expresa Sneider: "Que nuestra amistad sea para toda la vida". Pero ¿quién está preparado para estas situaciones? solamente se vive con la mejor actitud. Por tanto, los jóvenes acceden a Facebook como alternativa para sobrepasar el momento y continuar con su proceso de socialización.

Otro aspecto importante son las limitaciones que genera la sociedad, persecución, desprestigio y exposición cuando las ideologías no concuerdan con el sistema, los memes es el medio sutil para expresar verdades, resulta curioso una generación que se construye en la burla 
colectiva como mecanismo de participación y oposición. Dicho lo anterior Carolina expresa: "Ropa que quiero usar pero no puedo porque soy gorda". La belleza adquiere protagonismo importante en Facebook fotografías retocadas, posturas insinuantes que para las jóvenes se resume en cuerpos esculturales, fomentadas por ellas mismas (si comprendemos que una joven sigue a otra que en apariencia resulta más atractiva) fortalecidos en aplicaciones para videos, montajes fotográficos y escritura de red.

Esta escritura caracterizada por comenzar toda palabra con mayúscula rompe reglas gramaticales, dialécticas e incluso fonéticas, adicionalmente escriba en poco para entender mucho pone a prueba a generaciones anteriores. Perla con pseudónimo "Arroz con leche" comparte un meme abreviado acorde con la escritura juvenil: "Esas personas que escriben "Hla, Bn, Q,Ps, Nda" - ¿Qué hacen con el tiempo que se ahorran? En concreto, ¿Cómo entender sistemas cifrados de comunicación, en palabras medio escritas, con letras diferentes a su escritura original, llena de memes y gifs?, ¿Cómo enseñar a los jóvenes a diferenciar los espacios cuando estos se replican en la presencialidad y los jóvenes no prestan importancia a redactar y escribir adecuadamente un texto? En contraste con lo anterior, parece que los jóvenes publican poco pero el testigo de Messenger demuestra lo contrario.

De hecho, cuando se observan los perfiles de jóvenes, se observan diferencias. Los más jóvenes parecen explorar con mayor intensidad las posibilidades que ofrece la red social. Así, una mayor exploración de las posibilidades técnicas parece relacionarse también con una intensa exploración de los procesos de identificación juvenil. En personas jóvenes, aspectos de identificación y de construcción del universo social están en primer plano, lo mismo que las intencionalidades comunicativas y de mantenimiento y cuidado del vínculo con personas pertenecientes a la familia y el círculo de amigos. En definitiva, las imágenes en Facebook muestran como los jóvenes parecen asumir que los cambios físicos prevalece, ya que los jóvenes tienen la necesidad de experimentar con su propia autoimagen más allá de las reglas establecidas, escenificando y transformando su imagen para 
ser publicada, algo así como el canon biográfico que representa ser joven y como la imagen sigue estando en primer plano frente a sus seguidores.

Joven es joven, los aislamientos no impiden crear grupos que los identifiquen en relación con intereses, de esta manera un nombre gracioso, pegadizo o cuestionable no es impedimento para ser la diferencia de la red, los contenidos la estrategia para ser valorados positiva a negativamente. Habrá que esperar para saber la fuerza que adquiere estos seudónimos y contenidos, a lo mejor la verdadera realidad sea Facebook y la falsa, la que presenciamos en nuestros cuerpos de alquiler.

\section{Referencias bibliográficas.}

Almansa, A.; Fonseca, O. y Castillo, A. (2013). Redes sociales y jóvenes. Uso de Facebook en la juventud colombiana y española. Comunicar, 40, 127-135.

Ángel, D. (2011). La hermenéutica y los métodos de investigación en ciencias sociales. Estudios filosóficos, 44, 9-37.

Avendaño, J. (2017). Análisis del uso de la red social Facebook desde una perspectiva de identidad cultural en estudiantes de bachillerato de la Unidad Educativa Del Milenio Penipe en el periodo noviembre 2016 - febrero 2017. (Trabajo de grado). Universidad Nacional de Chimborazo, Ecuador.

Benítez, L.; Cortéz, E. y Hernández, C. (2016). El aislamiento social como consecuencia del uso excesivo del internet y móviles en adolescentes. Psicoeducativa: reflexiones y propuestas, 2(4), 2430.

Cabrales, O. y Díaz, V. (2017). El aprendizaje autónomo en los nativos digitales. Conhecimento \& Diversidade, 9(17), 12-32.

Canales, V. (2020). La participación ciudadana a través del Facebook de la municipalidad de Ate en tiempos del coronavirus, 2020. (Trabajo de grado). Universidad Cesar Vallejo, Perú.

Cassany, D. y Ayala, G. (2018). Nativos e inmigrantes digitales en la escuela. Participación educativa: revista del Consejo Escolar del Estado, 9(4), 57-75. 
Castillo D.; Núñez, R. y López, B. (2019). Aportes metodológicos de la etnografía digital latinoamericana basados en world of warcraft. Revista Uruguaya de Antropología y Etnografía, 4(1), 11-23. https://dx.doi.org/10.29112/ruae.v4.n1.2

Domínguez, M. (2018). La mejor cámara digital y el reconocimiento virtual. Estudio exploratorio sobre la imagen de perfil de Facebook de nativos e inmigrantes digitales Tabasqueños. (Trabajo de grado). Universidad Autónoma de Nuevo León, México.

Feixa, C. (2006). Generación XX. Teorías sobre la juventud en la era contemporánea. Revista Latinoamericana de Ciencias Sociales, Niñez y Juventud, 4(2), 1-18.

Galindo, L. (2016). Jóvenes activistas. Movimientos de protesta e Internet en Colombia y Brasil. Juvenopedia: mapeo de las juventudes Iberoamericanas. París: Editorial Ned.

Giddens, A. (1991). The consequences of Modernity. Cambridge: Polity Press.

Hall, S. \& Du Gay, P. (2011). Questions of Cultural Identity. Londres: Sage.

Hernández, R.; Fernández, C. y Baptista, P. (2004). Metodología de la investigación. México, D.F.: Editorial McGraw-Hill.

Muñoz, G. (2016). Jóvenes digitales. Cuerpos con agencia, en Colombia. Juvenopedia: mapeo de las juventudes Iberoamericanas. París: Editorial Ned.

Ortega, W. (2015). Ciudadanía digital: Entre la novedad del fenómeno y las limitaciones del concepto. Economía, sociedad y territorio, 15(49), 835-844.

Ramírez, J.; Castro, D.; Lerma, C.; Yela, F. y Escobar, F. (2020). Consecuencias de la pandemia COVID 19 en la salud mental asociadas al aislamiento social. Colombian Journal of Anesthesiology, 48(4), e930. https://doi.org/10.1590/SCIELOPREPRINTS.303

Reátegui, J. (2020). Uso de Facebook por internautas peruanos en la divulgación y viralización de videos de personas incumpliendo la 
cuarentena en Perú por el COVID-19. (Trabajo de grado). Universidad San Ignacio De Oyola, Perú.

Reyes, M. y Sosa, L. (2017). Memes de Facebook: una mirada desde el interaccionismo simbólico en adolescentes de un colegio distrital de Bogotá. Bogotá: Ediciones Fundación Universitaria Los Libertadores.

Roldan, M. (2015). Antecedentes sobre el uso de Facebook en adolescentes. (Trabajo de grado). Universidad de la República Uruguay, Uruguay.

Rueda, R., Giraldo, D. (2016). La imagen de perfil en Facebook: identidad y representación en esta red social. Folios, 43, 19-135.

Small, G. y Vorgan. (2009). El cerebro Digital. Cómo las nuevas tecnologías están cambiando nuestra mente. Barcelona: Ediciones Urano.

Van Dijck, J. (2008). Digital photography: communication, identity, memory. Visual Communication, 7(1), 57-76.

Vargas, A. (2016). Redes sociales, literacidad e identidad (es): el caso de Facebook. Revista colombiana de lingüística aplicada, 18(1), 1124. 